\title{
Ethik und christliche Identität bei Gregor von Nyssa
}

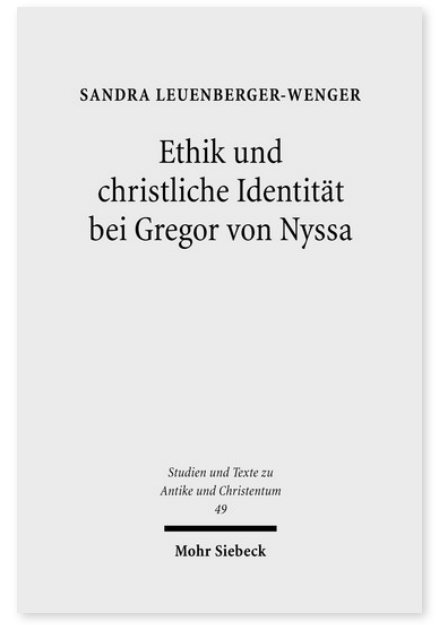

2008. IX, 426 Seiten. STAC 49

ISBN 978-3-16-151348-0

DOI 10.1628/978-3-16-151348-0

eBook PDF 109,00 €

ISBN 978-3-16-149677-6

fadengeheftete Broschur 109,00€
Sandra Leuenberger-Wenger untersucht die ethischen Reflexionen und Ratschläge Gregors von Nyssa, ihre unterschiedlichen Formen und ihre Bedeutung für die Vergewisserung christlicher Identität. Dabei zeigt sie, dass sich die Frage nach dem geglückten Leben in einer spezifisch christlichen Lebensweise mit wechselndem Adressatenkreis unterschiedlich stellte. Je nachdem, ob Gregor sich in Predigten an seine Gemeinde wandte oder Schriften für ein literarisches Publikum verfasste, ging er von unterschiedlichen Voraussetzungen und Interessen aus, welche sich in seiner Argumentationsweise niederschlagen. Die Mehrheit der Gemeinde musste zuerst von der Bedeutung einer guten christlichen Lebensweise überzeugt und dazu motiviert werden. Dagegen brachte das literarische Publikum Gregors sowohl Bildung als auch Interesse an einem möglichst vollkommenen christlichen Leben mit, zudem vielfach auch Kenntnisse von philosophischen Konzepten des guten Lebens, gegenüber denen das christliche überzeugen musste. Die Autorin stellt dar, wie Gregor gegenüber seinen unterschiedlichen Adressatenkreisen die Bedeutung eines guten christlichen Lebens aufzeigte und sich bemühte, seinen Adressaten ein Bewusstsein für christlich motiviertes Handeln zu vermitteln: Die Adressaten sollten sich sowohl durch ihr Handeln als auch durch die Begründung ihres Handelns vor sich und der Umwelt als Christen ausweisen. Auf der Grundlage seines Tugendbegriffs und seiner christlichen Anthropologie zeigte Gregor in unterschiedlichen Kontexten und anhand verschiedener Problemstellungen sozial- wie auch individualethischer Art auf, worin ein geglücktes christliches Leben besteht.

Sandra Leuenberger-Wenger Geboren 1976; Studium der Theologie in Zürich und Rom; 2002-2003 Vikariat bei der Zürcher Landeskirche; 2007 Promotion; seit 2008 Oberassistentin am Lehrstuhl für die Geschichte der Alten Kirche und des Mittelalters der Universität Zürich.

\section{Jetzt bestellen:}

https://mohrsiebeck.com/buch/ethik-und-christliche-identitaet-bei-gregor-von-nyssa-9783161513480?no_cache=1 order@mohrsiebeck.com

Telefon: +49 (0)7071-923-17

Telefax: $+49(0) 7071-51104$ 